\title{
Interspecific variation in palatability suggests cospecialization of antipredator defenses in sea hares
}

\author{
Kimberly K. Takagi ${ }^{1,2}$, Nadia N. Ono ${ }^{1,3}$, William G. Wright ${ }^{1, *}$ \\ ${ }^{1}$ Department of Biological Sciences, Chapman University, One University Dr., Orange, California 92866, USA \\ ${ }^{2}$ Present address: Laboratory of Ecology and Systematics, University of the Ryukyus, 1 Senbaru, Nishihara, \\ Okinawa 901-0213, Japan \\ ${ }^{3}$ Present address: Department of Plant Sciences, University of California - Davis, One Shields Avenue, Davis,
} California 95616, USA

\begin{abstract}
Prey species often deploy different kinds of antipredator defenses, which can interact with each other in ways that are not yet completely understood. Much research into these interactions has utilized gastropod mollusks, usually focusing (in part) on the protective utility of the gastropod shell. This makes the evolutionary reduction of the shell in the opisthobranch gastropods (marine slugs) particularly interesting. This loss of protective function of the shell is associated with the evolution of alternative defenses. Particularly well studied are chemical defenses, especially those using secondary metabolites derived from food resources. As a first step toward understanding interspecific variation in the deployment of multiple defenses, we compared the passive chemical defenses of 3 opisthobranchs (Aplysia californica, Phyllaplysia taylori, and Dolabrifera dolabrifera; hereafter referred to by their genus name). We homogenized the skin and body wall into standardized food pellets, and assayed the palatability of these pellets by measuring their consumption by a common intertidal hermit crab, Pagurus samuelis. This assay revealed significant variation in palatability. Pellets made from the skin and body wall of Phyllaplysia and Dolabrifera had higher palatability, indicating low levels of chemical protection, while pellets from Aplysia showed a 2-fold lesser palatability, indicating greater chemical protection. This phylogenetic variation in palatability is similar to previously reported variation in behavioral sensitization. Although the role of sensitization as a possible antipredator defense is yet poorly understood, these results on palatability raise the possibility that opisthobranchs may cospecialize defenses across species.
\end{abstract}

KEY WORDS: Chemical defense - Secondary metabolites · Natural selection · Behavioral sensitization · Niche specialization · Bioassay $\cdot$ Gastropoda

\section{INTRODUCTION}

Predator-prey relationships provide a window into evolution by natural selection. Species that are vulnerable to predation often evolve a variety of risk reducing adaptations (Alcock 2005). Because each adaptation has inherent utility, specificity, and cost, evolutionary biologists have sought to understand how these adaptations are adjusted when ecological circumstances change (DeWitt et al. 1999, DeWitt \& Langerhans 2003). Are all traits increased or decreased in concert, or is an increase in one defense traded off with a decrease in another?
Do the defenses complement each other or are they simply redundant? These questions can be asked within species, e.g. how do populations living in the presence of a predator adjust their array of defenses relative to predator-free populations; or between species, e.g. do species with a high investment in one kind of defense tend to invest more or less in other kinds of defenses?

Much of the previous research into multiple antipredator defenses has focused on species with morphological and behavioral adaptations to reduce predation risk. For example, DeWitt et al. (1999) examined gastropod shell-shape (relatively narrow shells de- 
crease vulnerability) and avoidance behavior (snails crawl out of pools when the scent of their crayfish predator is present). In the present study, we examined a lineage of gastropods (sea hares; Aplysiomorpha, Opisthobranchia) that has lost the ubiquitous protection of the shell (shells are reduced or absent). Instead, aplysiomorph opisthobranchs deploy the more specialized protection afforded by repugnant secondary chemical compounds (Faulkner \& Ghiselin 1983, Gerwick \& Whatley 1989, Avila 1995, Ginsburg \& Paul 2001, Penney 2002, Wagele et al. 2006). This chemical protection includes a combination of passive defense from chemicals in the epithelium and body wall (Pennings \& Paul 1993, Pennings 1994, Pennings et al. 1999, Spinella et al. 2002), and active defense due to behavioral secretion of ink and opaline from specialized glands (Nolen et al. 1995, Nolen \& Johnson 2001, Kicklighter et al. 2005, Kicklighter \& Derby 2006, Derby 2007, Kicklighter et al. 2007). It also includes a wide range of bioactive secondary metabolites in the digestive gland (Stallard \& Faulkner 1974, Pennings 1994, Ginsburg \& Paul 2001). Thus, the evolution of chemical defenses in lieu of the physical protection of a shell presents an opportunity to broaden our understanding of how multiple defenses are deployed.

As a first step, we examined the passive chemical defenses of 3 species spanning the phylogeny of the aplysiomorph opisthobranchs: Aplysia californica, Phyllaplysia taylori, and Dolabrifera dolabrifera (hereafter referred to by their genus name). Although chemical defenses have been well studied in Aplysia and its relatives (Carefoot 1987, Pennings 1994, Avila 1995, Nolen \& Johnson 2001, Kicklighter et al. 2005, Nusnbaum \& Derby 2010), chemical defenses in Phyllaplysia and Dolabrifera have been scarcely studied (Ciavatta et al. 1996). We chose these 3 species (Phyllaplysia and Dolabrifera are sister genera in the subfamily Dolabriferinae, and Aplysia is a more distant relative in the subfamily Aplysiinae; Klussmann-Kolb 2004) because we have previously discovered significant variation among them in a simple form of learning called sensitization (Wright et al. 1996, Wright 1998, Erixon et al. 1999, Marinesco et al. 2003). Sensitization refers to a generalized increase in reflex response after a novel or noxious stimulus (Kandel 2004, Barco et al. 2006). We hypothesized that this form of learning may provide some protection against predators (see 'Discussion'). In the present study, we asked whether these 3 species also show similar variation in passive chemical defense.

\section{MATERIALS AND METHODS}

Collection information. Individuals of Aplysia were collected from the subtidal (0 to $20 \mathrm{~m}$ ) off Palos Verdes
Peninsula by Alacrity Marine Biological Services, Redondo Beach, California, USA, between April 2003 and August 2004. Aplysia inhabits a wide range of habitats ranging from sand/rubble to high-relief rocky kelp beds on unprotected coasts (see 'Discussion'). During the same months, individuals of Phyllaplysia were collected from eelgrass beds in enclosed bays of San Juan Island, Puget Sound, Washington, USA (D. Duggins, Friday Harbor Labs; see 'Discussion'). Individuals of Dolabrifera were collected from under barely movable boulders next to the shoreline, inshore of coral reefs (primarily Blacks Point, near Honolulu) in Kaneohe, Hawaii, USA (K. Maruska, University of Hawaii). Finally, individuals of the small (5 to $10 \mathrm{~mm}$ carapace length), omnivorous detritivorous (Hazlett 1981) hermit crab Pagurus samuelis were collected near Newport Harbor, California, from high-intertidal outer-coast tidepools (Ricketts et al. 1992), and used in experiments within $4 \mathrm{~d}$ of collection. All individuals were maintained in recirculating artificial sea water (ASW; Instant Ocean, Aquarium Systems). Cold-water aquaria were kept at 13 to $17^{\circ} \mathrm{C}$ (separate aquaria for sea hares and hermit crabs) whereas the warm-water aquarium (housing only Dolabrifera) was maintained at 20 to $23^{\circ} \mathrm{C}$.

Laboratory assays. In order to assay the palatability of each of the 3 sea hare species, we made standard food pellets from 5 to 10 individuals of each of the 3 species, following the procedure of O'Neal \& Pawlik (2002). These individuals were made into pellets within $2 \mathrm{~d}$ of capture and were not fed during this time. In order to best reflect the passive chemical defenses of the 3 sea hare species, we removed the mantle (including ink and opaline glands), all viscera, the nervous system, and the head of each individual. We rinsed the remaining skin and body wall tissue (including the parapodia, the bottom of the foot, and body wall musculature) in ASW and blended it in a food processor (Cuisinart). The resulting body wall paste was spread thinly ( $\sim 1$ to $2 \mathrm{~mm}$ in depth) on wax paper and frozen at $-80^{\circ} \mathrm{C}$. Samples were freezedried in 6.0 to $12.0 \mathrm{~g}$ frozen pieces (Dura-Dry MP, FTS Systems). Once dried, the tissue was powdered with a mortar and pestle. We then combined $0.50 \mathrm{~g}$ of this powdered tissue and $0.30 \mathrm{~g}$ of powdered alginic acid with deionized water to yield a total volume of $10 \mathrm{ml}$. We then added $0.5 \mathrm{ml}$ of food coloring (McCormick) to differentiate Aplysia, Phyllaplysia, and Dolabrifera pellets. Previous research on squid (Gilly \& Lucero 1992) found that the fixative in food coloring, propylparaben, acted as an irritant, i.e. induced escape behavior, at a threshold of $10 \mathrm{mM}$. This is $>200 \times$ the estimated concentration of propylparaben $(0.03 \mathrm{mM})$ in our pellets. The homogenized gelatinous mixture was poured into a $10 \mathrm{ml}$ syringe 
and injected into a $0.25 \mathrm{M}$ calcium chloride solution. The spaghetti-like strand was allowed to harden before rinsing in ASW. The strand $(\sim 2.0 \mathrm{~mm}$ diameter) was cut into $10 \mathrm{~mm}$ lengths and placed in the refrigerator. After $48 \mathrm{~h}$, the pellets were frozen individually in 0.5 or $1.0 \mathrm{ml}$ micro-centrifuge tubes and stored in the freezer at $-80^{\circ} \mathrm{C}$ until use. The same process was conducted to create squid pellets (mantle only) from commercially purchased frozen squid.

In order to test whether individual crabs were hungry, we first presented squid pellets to candidate crabs. Only crabs that began to eat these pellets ( $60 \%$ of crabs) were used. For each trial, we poured $60 \mathrm{ml}$ of freshly made ASW into each of 11 plastic cups (bottom diameter $=7 \mathrm{~cm}$, or 3 to 5 hermit crab shell lengths across). All food pellets were thawed in $17^{\circ} \mathrm{C}$ ASW, after which they were allowed to dry on a coffee filter for $2 \mathrm{~min}$, and weighed to the nearest $0.001 \mathrm{~g}$ (pellets weighed between 0.015 and $0.030 \mathrm{~g}$ ). We then placed one of these pellets into each cup. Single individuals of the assay organism, the hermit crab Pagurus samuelis, were placed in the first 8 cups. To control for changes in pellet weight in the absence of crab feeding, we left 3 cups without any crab (blank controls). After $30 \mathrm{~min}$, we dislodged any remaining material held by each crab, and placed the crab in a clean cup with $60 \mathrm{ml}$ of ASW in preparation for the second trial. We poured the contents of the original cup onto a coffee filter, allowed it to dry for $2 \mathrm{~min}$, and weighed all visible pellet pieces remaining. The amount eaten was calculated as the initial weight minus that remaining at the end of the session. After a $1 \mathrm{~h}$ break, we placed a second pellet (feeding session \#2) into each cup and ran an identical second trial.

In order to test whether this protocol changed the feeding propensity in each hermit crab, i.e. satiation resulting in less consumption during the second trial, or sensitization resulting in more consumption, we performed an experiment in which each crab was presented with pellets of the 'same' species in consecutive trials (Phyllaplysia and Aplysia only).

In the next 2 experiments, individual crabs were consecutively presented with pellets of 2 different species: Aplysia and Phyllaplysia in one experiment; Aplysia and Dolabrifera in the other. In each experiment, half of the crabs were presented with the pellet from one species first, and the other half with the pellet from the other species first.

Statistical analysis. For each feeding trial, we corrected the weight loss of experimental pellets (those available to a hermit crab for $30 \mathrm{~min}$ ) by subtracting the average weight loss of the 3 blank controls to determine the amount of the pellet consumed. A paired $t$-test was conducted to determine whether pellet weight was significantly diminished by feeding. An additional paired $t$-test compared the pellet consumption between the first and second feeding sessions. Between-experiment comparisons were made with an independent-samples 2-sample $t$-test.

\section{RESULTS}

We first tested whether hermit crabs consumed pellets similarly in consecutive trials. Crabs did not appear to become satiated, or sensitized, by the first feeding. Instead, successive $30 \mathrm{~min}$ feeding trials showed very similar consumption (Fig. 1), regardless of whether the amount eaten was minimal (Aplysia) or substantial (Phyllaplysia). This consistency across feeding trials allowed the use of a much more powerful repeated measures experimental design for betweenspecies comparisons (see below). Note that the average consumption of Aplysia pellets did not reach statistical significance, whereas consumption of Phyllaplysia pellets did.

In Fig. 2, the pellet-consumption data from both trials in Fig. 1 were averaged for each crab and the overall average pellet consumption for each species directly compared. This comparison showed that hermit crabs consumed greater amounts of Phyllaplysia than Aplysia pellets. However, because the averages for each species were calculated based on experiments with different groups of crabs, we conducted sequential feeding trials, in which we fed pellets made from the 2 different sea hare species to each crab. Eight crabs were fed with Aplysia pellets first, followed by Phyllaplysia pellets. Eight additional crabs were fed with Phyllaplysia pellets first, followed by Aplysia pellets. Because the order of presentation had no discernible effect, we combined these experiments in Fig. 3. Crabs consumed significant amounts of both species, but consumed $\sim 50 \%$ more Phyllaplysia than Aplysia pellets.

We next performed equivalent balanced experiments with Dolabrifera and Aplysia pellets. The combined data set clearly shows that crabs consumed a substantially greater mass of Dolabrifera than Aplysia pellets (Fig. 4).

It is important to note that although the consumption of Aplysia pellets in this final experiment was statistically significant, the average consumption $(0.0037 \pm$ $0.0006 g_{;}$Fig. 4) was only half that of the Aplysia pellets in the previous set of experiments $(0.0079 \pm$ 0.0019 g; Fig. 3 ; independent-samples $t$-test: $t=2.08$, $\mathrm{p}<0.05, \mathrm{n}=16,16)$. Thus, it appears that crab feeding is variable from week to week, underlining the importance of our decision to make direct comparisons by feeding pellets of 2 different species to the same individual crabs over a restricted time period ( 2 to $3 \mathrm{~h}$ ). 

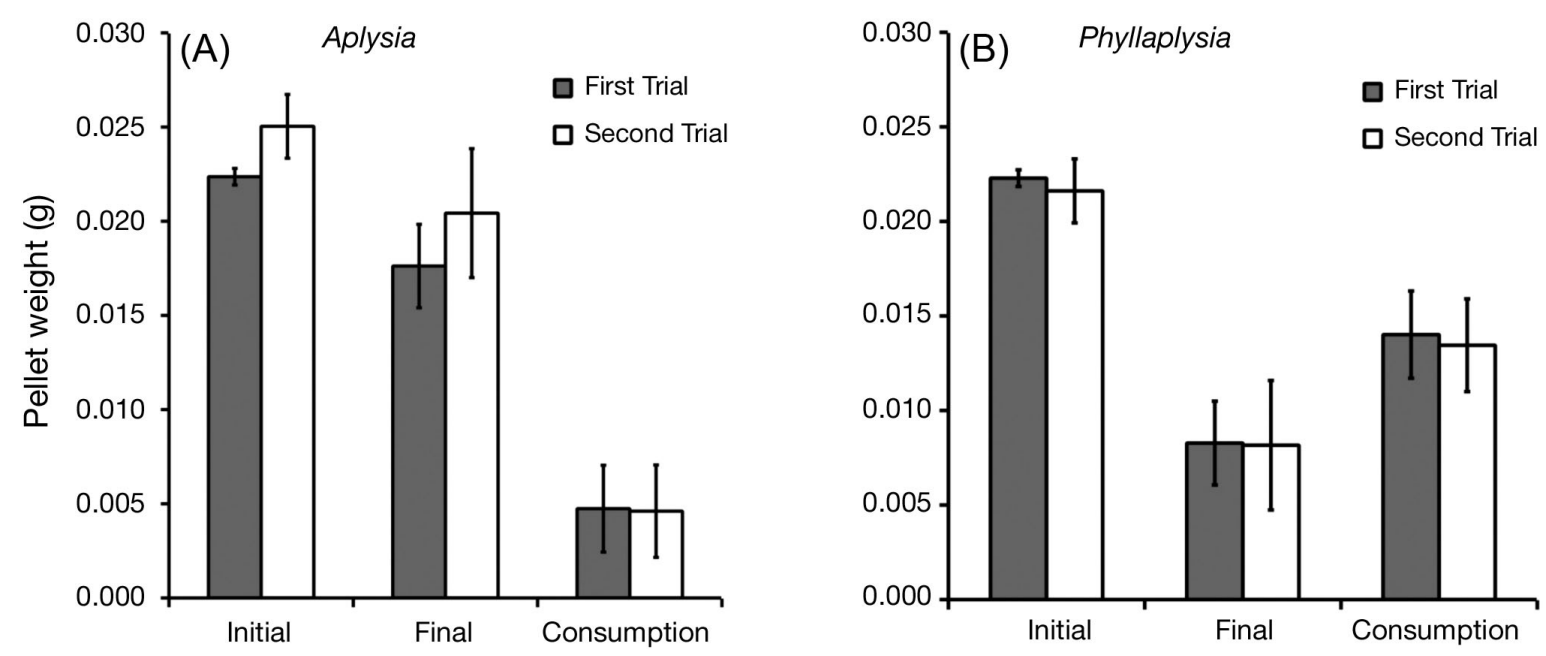

Fig. 1. Consumption of pellets derived from the same sea hare species by individual hermit crabs during 2 sequential 30 min trials. Pellet weight before (Initial weight) and after (Final weight) 30 min feeding trials is shown. The change in pellet weight during each trial (Consumption = Initial minus Final weight) is also shown. (A) Feeding on Aplysia californica pellets. Hermit crab consumption during sequential trials was indistinguishable, indicating neither satiation, nor priming by the first exposure. Although the average pellet weight decreased in both trials, the decreases were not significant (repeated measures $t$-test on combined data; $\mathrm{p}=0.073, \mathrm{~N}=8$ ). (B) Equivalent feeding on Phyllaplysia taylori pellets. Consumption during sequential trials was again indistinguishable. However, this time, the decrease in pellet weight was significant $(\mathrm{N}=8, \mathrm{p}=0.0002)$. Mean $\pm \mathrm{SE}$ are depicted in this and all subsequent figures

\section{DISCUSSION}

Despite a very large literature on natural products and chemical defenses of Aplysia californica and other members of the genus (see Carefoot 1987, Pennings \& Paul 1993, Pennings 1994, Avila 1995, Wagele et al. 2006), very little is published on chemical defense in Dolabrifera (Ciavatta et al. 1996), and nothing on

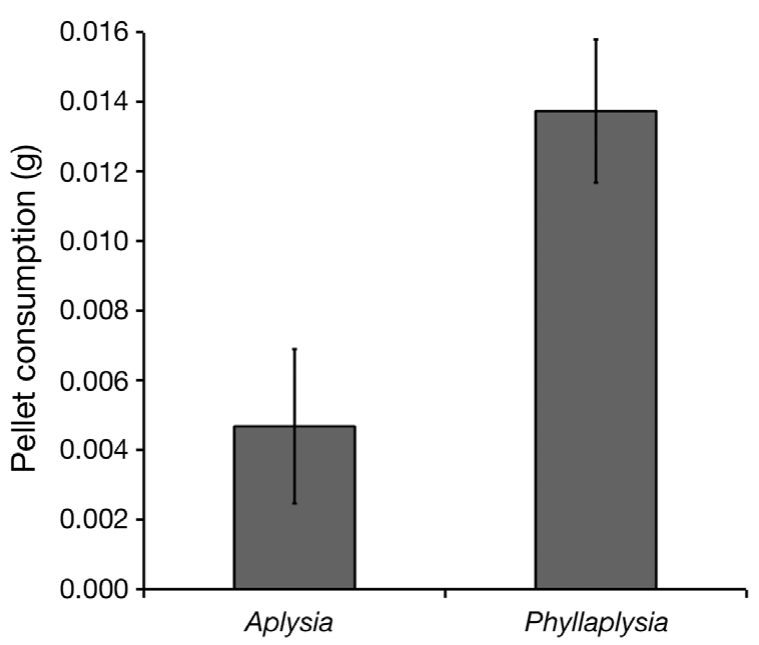

Fig. 2. Cross-species comparison of data in Fig. 1. Crab consumption of pellets derived from Aplysia vs. those from Phyllaplysia was averaged for the 2 successive trials. Crabs ate significantly more Phyllaplysia than Aplysia (2-sample $t$-test; $\mathrm{N}=8,8 ; \mathrm{p}=0.010$ ) chemical defense in Phyllaplysia. Thus, although many of the studies on other opisthobranchs may generalize to Dolabrifera and Phyllaplysia, they give no basis for possible contrast.

The experiments reported here document significant variation in the palatability of pellets made from the skin and body wall of 3 sea hare species: Aplysia pellets were less palatable than either Phyllaplysia or

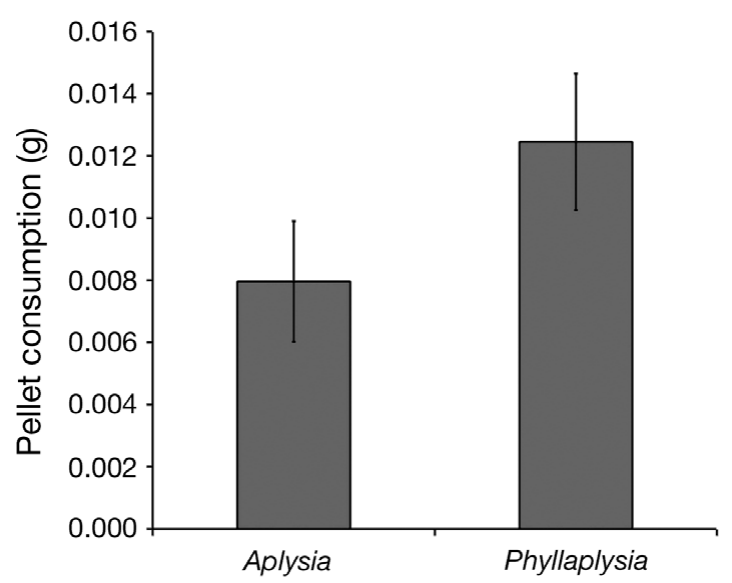

Fig. 3. Repeated measures design confirms that hermit crabs eat pellets of Phyllaplysia more readily than pellets of Aplysia. Hermit crabs (16) were fed either with Phyllaplysia followed by Aplysia or vice versa ( $\mathrm{N}=8$ for both). Shown is the average consumption of pellets for the 2 species. Crabs ate significantly more Phyllaplysia than Aplysia (repeated measures $t$-test; $\mathrm{N}=16, \mathrm{p}=0.015$ ) 


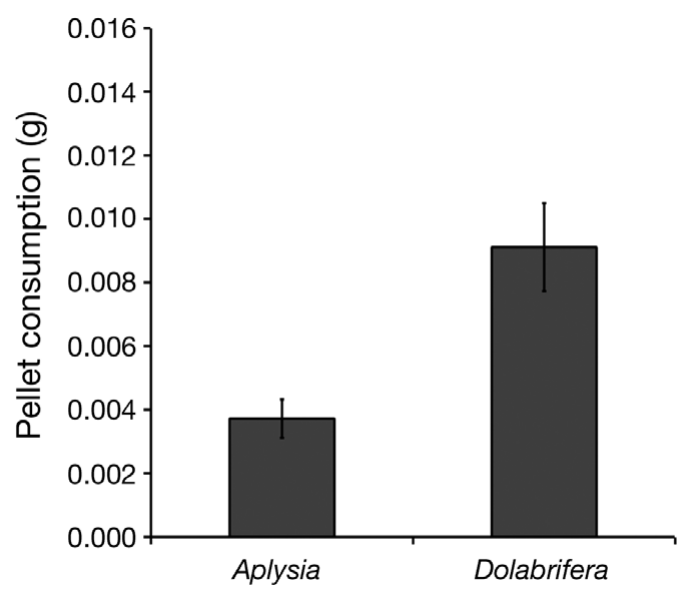

Fig. 4. Hermit crabs eat pellets of Dolabrifera more readily than pellets of Aplysia. Data collected as in Fig. 3. Consumption of Dolabrifera pellets was significantly greater than that of Aplysia pellets (repeated measures $t$-test; $\mathrm{N}=16, \mathrm{p}=0.0014$ )

Dolabrifera pellets. This variation suggests that Aplysia has more passive chemical protection than the other 2 genera.

There are a number of caveats to consider in this interpretation. First, these experiments did not evaluate all the chemical defenses these species deploy. Indeed, we explicitly removed ink and opaline glands during the dissection, because they are components of active, rather than passive, defense. Internal organs (e.g. digestive glands), some of which are known to contain high concentrations of unpalatable metabolites (Stallard \& Faulkner 1974, Carefoot 1987, Avila 1995, Ginsburg \& Paul 2001), were also excluded from the pellets because they cannot actually protect the attacked sea hare (entry by a predator into the haemocoel that contains these organs kills the sea hare; Pennings \& Paul 1993, Pennings et al. 2001). Thus, we only included the skin and body wall of the sea hares because this is the first tissue that would be encountered as a predator bites the individual.

Second, virtually any assay organism will have potential problems, and Pagurus samuelis is no exception. We purposely chose this omnivorous detritivore (Hazlett 1981, Ricketts et al. 1992), rather than a predator specific to any one of the 3 species, in an effort to avoid any obvious consumer bias. Nevertheless, the fact that $P$. samuelis co-occurs to some extent with Aplysia along the California coast (Ricketts et al. 1992) raises the possibility that interactions with Aplysia (across evolutionary or ontogenetic time) may predispose the hermit crab to selectively reject Aplysia pellets. Hermit crabs, like most omnivores, can learn to avoid foods that make them sick (Wight et al. 1990), and it is possible that such learned aversion could account for the feeding differences we observed. How- ever, the low density of Aplysia across time and space in hermit crab habitats (W. G. Wright pers. obs.) suggests that such learning events, if they occur at all, are almost certainly very rare. We note that sequential feeding of sea hare pellets in our experiments showed no evidence, at least on the time scale of tens of minutes, of acquired aversion or affinity (Fig. 1), thus excluding a phenotypically plastic response acting on a short time scale.

Third, even if this measure of passive chemical defense reflects the relative chemical protection of each species, it may not necessarily reflect their vulnerability to predation in their natural habitats. For example, the tropical to subtropical distribution of the wrasse family (Labridae), which is arguably the most likely among fish families to consume sea hares (Pennings 1990, Ginsburg \& Paul 2001, Pennings et al. 2001), suggests that sea hares in tropical waters (e.g. Dolabrifera) may be more at risk than those in subtropical waters (e.g. Aplysia). The latter may in turn be more at risk than those in temperate waters (Phyllaplysia). This logic would suggest that the significantly decreased protection of Dolabrifera (Fig. 4) in the face of an abundance of potentially dangerous wrasse species is particularly significant (see below). On the other hand, the fact that Phyllaplysia is less protected than Aplysia might simply reflect reduced predation intensity for the former species. These conjectures aside, the general observation that different sea hare species are likely to have quite different natural predators suggests the need for circumspection in extrapolating these results to assess predation risk.

Fourth, there is a possibility that the relatively reduced consumption of Aplysia pellets by Pagurus samuelis is a consequence of specific, perhaps arbitrary, tolerance of the pellets of the other 2 species. Such arbitrary specificity is much more common in primary herbivores than in consumers. Aplysia, for example, tolerates the chemical protectants of its preferred food (Plocamium carilagineum and Laurencia pacifica; Pennings 1990). However, such selectivity is not widely observed among consumers of chemically protected prey, especially if they are generalists as in the case of P. samuelis.

Given the above caveats, it is still worthwhile to conjecture upon the ecological factors that might select for this interspecific variation in palatability. The sparse ecological literature on Phyllaplysia and Dolabrifera suggests that they are niche specialists, and may thereby avoid predation by their choice of habitat, perhaps making other antipredator defenses less important. In particular, individuals of Dolabrifera lie well protected on the undersides of barely moveable boulders in shallow water, until they come out to forage for algae and diatoms. In Hawaii, individual Dolabrifera 
forage almost exclusively at night (Kay 1979, W. G. Wright pers. obs.), thereby presumably avoiding visual predators. The hypothesis that Dolabrifera avoids predation by its habitat and habits thereby making other defenses unnecessary is further supported by the observation that this genus has lost the ability to release ink (Prince \& Johnson 2006). This lack of active chemical defense in Dolabrifera is consistent with the low level of passive chemical defense documented in the present study.

Similar to Dolabrifera, individuals of Phyllaplysia also live in a specialized habitat (the fronds of seagrass; Ricketts et al. 1992). Phyllaplysia is exceedingly well camouflaged on these fronds, perhaps minimizing attacks by visual terrestrial predators. In addition, Phyllaplysia's seagrass habitat removes individuals from the benthos at high tide, when the majority of nonvisual predators (primarily crabs and shrimp) forage.

In contrast to the relatively specialized habitats of Dolabrifera and Phyllaplysia, the habitat of adult Aplysia is distributed throughout the rock and rubble littoral zone (intertidal to $20 \mathrm{~m}$; Carefoot 1987, Ricketts et al. 1992). Although Aplysia is generally well camouflaged, individuals are constantly in potential contact with a wide range of predators, both non-visual (lobsters, Pennings 1990; pycnogonid crabs, Rogers et al. 2000), and visual (several fish species, Pennings 1990).

Finally, the original motivation for executing these experiments was physiological research in our laboratory, which found significant phylogenetic variation in mechanisms of sensitization across 7 aplysiomorph species (Wright et al. 1996, Erixon et al. 1999), as well as behavioral experiments verifying correlated variation in behavioral phenotypes (Wright 1998, Erixon et al. 1999, Marinesco et al. 2003). Sensitization is a simple form of learning, which refers to the strengthening of defensive reflexes following a noxious stimulus. Although it is robust in Aplysia (Marcus et al. 1988, Wright 1998), our work established it to be absent in Dolabrifera (Wright 1998), and much reduced in Phyllaplysia (Erixon et al. 1999).

We hypothesized (Wright 1998) that sensitization subsequent to a sublethal predatory attack may reduce the risk of predation. Although this hypothesis remains untested, we have recently demonstrated that Aplysia is sensitized by a sublethal attack from the California spiny lobster Panulirus interruptus (Ross et al. 2006, Watkins et al. 2010) and the predatory sea slug Navanax inermis (Thomas et al. 2006). Given that sensitization has a protective function against predators, it is interesting to compare its interspecific distribution to that of palatability, as demonstrated in the present study. Here, we found that pellets from the 2 genera with reduced sensitization, i.e. Phyllaplysia and Dolabrifera, were also less protected. In contrast, pellets made from Aplysia, the genus with robust sensitization, were more protected. The co-occurrence of these 2 defense-related traits suggests that they may represent cospecialized defenses (DeWitt et al. 1999, Mikolajewski \& Johansson 2004, Hammill et al. 2009). DeWitt et al. (1999) proposed that cospecialization, which is the codeployment of 2 or more antipredator defenses, might reflect strong heterogeneity in predation risk. Populations (or species) with little or no predation would be expected to dispense with all defenses, while those with a strong predator presence would be expected to deploy an array of different defenses.

Thus, we propose that opisthobranch species with narrow, specialized habitats may be able to persist with few or no antipredator defenses, whereas species with unspecialized, broad habitats may require chemical as well as behavioral defenses. Other behavioral defenses, in addition to sensitization, are quite likely. For example, avoidance (Dayton 1973, Vance \& Schmitt 1979, DeWitt \& Langerhans 2003, Cotton et al. 2004) and escape (Feder 1963, Walters et al. 1979, DeWitt \& Langerhans 2003) may be triggered by the chemical stimulus of a predator, or by the actual experience of surviving an attack. Thus, sensitization could very well be a part of an ensemble of behavioral changes associated with impending or recently experienced predator attacks.

This interpretation assumes that chemical and behavioral defenses are independent (additive) in their effects on predators. However, further studies may reveal that they have a mechanistic or behavioral dependence that can create a synergistic interaction. For example, a highly sensitized Aplysia responds to tactile stimuli by withdrawing all extremities so strongly that the individual becomes almost spherical. If the distribution of unpalatable compounds were found to be selectively concentrated in the region of the sea hare that is exposed in the 'balled up' state, a much more unpalatable target might result. Such a coordinated deployment of defenses (sensitization and chemical protection) would be more accurately regarded as codependence (DeWitt et al. 1999), which is an intuitively more easily understood adaptive response.

Finally, our observation of a positive relation between sensitization and chemical defense raises the possibility that the developmental assembly of the mechanisms underlying these 2 defenses may involve common elements. Our growing understanding of the metabolic pathways that sequester and transform ingested metabolites into protective chemicals (Fontana 2006), combined with our exceedingly rich understanding of mechanisms required for sensitization (reviewed by Kandel 2004, Barco et al. 2006), enhances the prospects of discovering functional connections 
between common elements. Such a discovery would constitute a first glimpse into the mechanisms underlying behavioral cospecialization.

Acknowledgements. We thank the members of the Wright Laboratory, especially B. Hoover, A. Ochoa, and B. Freitas for technical assistance and support throughout the research process.

\section{LITERATURE CITED}

Alcock J (2005) Animal behavior: an evolutionary approach, 8th edn. Sinauer, Sunderland, MA

Avila C (1995) Natural products of opisthobranch molluscs: a biological review. Oceanogr Mar Biol Annu Rev 33: 487-559

Barco A, Bailey CH, Kandel ER (2006) Common molecular mechanisms in explicit and implicit memory. J Neurochem 97:1520-1533

Carefoot TH (1987) Aplysia: its biology and ecology. Oceanogr Mar Biol Annu Rev 25:167-284

Ciavatta ML, Gavagnin M, Puliti R, Cimino G, Martinez E, Ortea J, Mattia CA (1996) Dolabriferol: a new polypropionate from the skin of the anaspidean mollusc Dolabrifera dolabrifera. Tetrahedron 52:12831-12838

> Cotton PA, Rundle SD, Smith KE (2004) Trait compensation in marine gastropods: shell shape, avoidance behavior, and susceptibility to predation. Ecology 85:1581-1584

Dayton PK (1973) Two cases of resource partitioning in an intertidal community: making the right prediction for the wrong reason. Am Nat 107:662-670

Derby CD (2007) Escape by inking and secreting: marine molluscs avoid predators through a rich array of chemicals and mechanisms. Biol Bull 213:274-289

- DeWitt TJ, Langerhans RB (2003) Multiple prey traits, multiple predators: keys to understanding complex community dynamics. J Sea Res 49:143-155

DeWitt TJ, Sih A, Hucko JA (1999) Trait compensation and cospecialization in a freshwater snail: size, shape and antipredator behaviour. Anim Behav 58:397-407

Erixon NJ, Demartini LJ, Wright WG (1999) Dissociation between sensitization and learning-related neuromodulation in an aplysiid species. J Comp Neurol 408:506-514

Faulkner DJ, Ghiselin MT (1983) Chemical defense and evolutionary ecology of dorid nudibranchs and some other opisthobranch gastropods. Mar Ecol Prog Ser 13:295-301

Feder HM (1963) Gastropod defensive responses and their effectiveness in reducing predation by starfish. Ecology 44:505-512

Fontana A (2006) Biogenetical proposals and biosynthetic studies on secondary metabolites of opisthobranch molluscs. In: Cimino G, Gavagnin M (eds) Molluscs: from chemo-ecological study to biotechnological application. Springer, Berlin, p 303-328

Gerwick WH, Whatley G (1989) Aplysia sea hare assimilation of secondary metabolites from brown seaweed, Stypopodium zonale. J Chem Ecol 15:677-683

Gilly WF, Lucero MT (1992) Behavioral responses to chemical stimulation of the olfactory organ in the squid Loligo opalescens. J Exp Biol 162:209-229

Ginsburg DW, Paul VJ (2001) Chemical defenses in the sea hare Aplysia parvula: importance of diet and sequestration of algal secondary metabolites. Mar Ecol Prog Ser 215:261-274

> Hammill E, Kratina P, Anholt B (2009) Non-lethal presence of predators modifies morphology and movement rates in
Euplotes. Hydrobiologia 621:183-189

Hazlett BA (1981) The behavioral ecology of hermit crabs. Annu Rev Ecol Syst 12:1-22

> Kandel ER (2004) The molecular biology of memory storage: a dialog between genes and synapses. Biosci Rep 24: $475-522$

Kay A (1979) Hawaiian marine shells. Bernice Pauahi Bishop Museum, Honolulu, HI

Kicklighter CE, Derby CD (2006) Multiple components in ink of the sea hare Aplysia californica are aversive to the sea anemone Anthopleura sola. J Exp Mar Biol Ecol 334: 256-268

> Kicklighter CE, Shabani S, Johnson PM, Derby CD (2005) Sea hares use novel antipredatory chemical defenses. Curr Biol 15:549-554

Kicklighter CE, Germann M, Kamio M, Derby CD (2007) Molecular identification of alarm cues in the defensive secretions of the sea hare Aplysia californica. Anim Behav 74: 1481-1492

Klussmann-Kolb A (2004) Phylogeny of the Aplysiidae (Gastropoda, Opisthobranchia) with new aspects of the evolution of seahares. Zool Scr 33:439-462

> Marcus EA, Nolen TG, Rankin CH, Carew TJ (1988) Behavioral dissociation of dishabituation, sensitization and inhibition in Aplysia. Science 241:210-213

Marinesco S, Duran KL, Wright WG (2003) Evolution of learning in three aplysiid species: differences in heterosynaptic plasticity contrast with conservation in serotonergic pathways. J Physiol-London 550:241-253

> Mikolajewski DJ, Johansson F (2004) Morphological and behavioral defenses in dragonfly larvae: trait compensation and cospecialization. Behav Ecol 15:614-620

Nolen TG, Johnson PM (2001) Defensive inking in Aplysia spp.: multiple episodes of ink secretion and the adaptive use of a limited chemical resource. J Exp Biol 204: 1257-1268

Nolen TG, Johnson PM, Kicklighter CE, Capo T (1995) Ink secretion by the marine snail Aplysia californica enhances its ability to escape from a natural predator. J Comp Physiol A 176:239-254

Nusnbaum M, Derby CD (2010) Ink secretion protects sea hares by acting on the olfactory and nonolfactory chemical senses of a predatory fish. Anim Behav 79:1067-1076

O'Neal W, Pawlik JR (2002) A reappraisal of the chemical and physical defenses of Caribbean gorgonian corals against predatory fishes. Mar Ecol Prog Ser 240:117-126

Penney BK (2002) Lowered nutritional quality supplements nudibranch chemical defense. Oecologia 132:411-418

> Pennings SC (1990) Multiple factors promoting narrow host range in the sea hare, Aplysia californica. Oecologia 82: 192-200

Pennings SC (1994) Interspecific variation in chemical defenses in the sea hares (Opisthobranchia: Anaspidea). J Exp Mar Biol Ecol 180:203-219

Pennings SC, Paul VJ (1993) Sequestration of dietary secondary metabolites by three species of sea hares: location, specificity, and dynamics. Mar Biol 117:535-546

Pennings SC, Paul VJ, Dunbar DC, Hamann MT, Lumbang WA, Novack B, Jacobs RS (1999) Unpalatable compounds in the marine gastropod Dolabella auricularia: distribution and effect of diet. J Chem Ecol 25:735-755

Pennings SC, Nastisch S, Paul VJ (2001) Vulnerability of sea hares to fish predators: importance of diet and fish species. Coral Reefs 20:320-324

> Prince JS, Johnson PM (2006) Ultrastructural comparison of Aplysia and Dolabrifera ink glands suggests cellular sites of anti-predator protein production and algal pigment processing. J Molluscan Stud 72:349-357 
Ricketts EF, Calvin J, Hedgpeth JW (1992) Between Pacific tides. Stanford University Press, Palo Alto, CA

Rogers CN, de Nys R, Steinberg PD (2000) Predation on juvenile Aplysia parvula and other small anaspidean, ascoglossan, and nudibranch gastropods by pycnogonids. Veliger 43:330-337

Ross F, Wilder L, Tillet SL, Wright WG (2006) Sub-lethal attack by Panulirus interruptus (Crustacea) produces sensitization in Aplysia californica. Program No 813.11. 2006 Neuroscience Meeting, Atlanta, GA. Society for Neuroscience, Washington, DC

Spinella A, Caruso T, Coluccini C (2002) First total synthesis of natural aplyolides $\mathrm{B}$ and $\mathrm{D}$, ichthyotoxic macrolides isolated from the skin of the marine mollusk Aplysia depilans. Tetrahedron Lett 43:1681-1683

Stallard MO, Faulkner DJ (1974) Chemical constituents of the digestive gland of the sea hare, Aplysia californica. I. Importance of diet. Comp Biochem Physiol 49:25-35

Thomas CS, Rodriguez A, Tillett SL, Wright WG (2006) Sublethal attack by Navanax inermis (Phylum Mollusca) produces sensitization in Aplysia californica. Program No 813.11. 2006 Neuroscience Meeting, Atlanta, GA. Society

Editorial responsibility: Joseph Pawlik, Wilmington, North Carolina, USA for Neuroscience, Washington, DC

> Vance RR, Schmitt RJ (1979) The effect of the predator-avoidance behavior of the sea urchin, Centrostephanus coronatus. Oecologia 44:21-25

Wagele H, Ballesteros M, Avila C (2006) Defensive glandular structures in opisthobranch molluscs: from histology to ecology. Oceanogr Mar Biol Annu Rev 44:197-276

Walters ET, Carew TJ, Kandel ER (1979) Classical conditioning in Aplysia californica. Proc Natl Acad Sci USA 76: 6675-6679

Watkins AJ, Goldstein DA, Lee LC, Pepino CJ and others (2010) Lobster attack induces sensitization in the sea hare, Aplysia californica. J Neurosci 30:11028-11031

- Wight K, Francis L, Eldridge D (1990) Food aversion learning by the hermit crab, Pagurus granosimanus. Biol Bull 178: 205-209

Wright WG (1998) Evolution of nonassociative learning: behavioral analysis of a phylogenetic lesion. Neurobiol Learn Mem 69:326-337

Wright WG, Kirschman D, Rozen D, Maynard B (1996) Phylogenetic analysis of learning-related neuromodulation in molluscan mechanosensory neurons. Evolution 50: 2248-2263

Submitted: February 8, 2010; Accepted: July 18, 2010

Proofs received from author(s): September 24, 1010 